\title{
CpG Immunotherapy in Chenopodium album sensitized mice: The comparison of IFN-gamma, IL- IO and IgE responses in intranasal and subcutaneous administrations
}

\author{
Tahereh Mousavi*1, Nader Tajik ${ }^{1}$, Maziar Moradi ${ }^{2}$ and \\ Masoomeh Fallah Radjabzadeh ${ }^{1}$
}

Address: ${ }^{1}$ Department of Immunology, Iran University of medical sciences, Shahid Hemmat highway 14496, Tehran, Iran and ${ }^{2}$ Department of Social Medicine, Iran university of Medical Sciences, Shahid Hemmat highway 14496, Tehran, Iran

Email: Tahereh Mousavi* - mousavi36@yahoo.com; Nader Tajik - nadertajik@yahoo.com; Maziar Moradi - mousavi@hotmail.com;

Masoomeh Fallah Radjabzadeh - nadertajik@yahoo.com

* Corresponding author

Published: 17 September 2008

Clinical and Molecular Allergy 2008, 6:10 doi:10.1186/1476-796I-6-10
Received: 13 April 2008

Accepted: 17 September 2008

This article is available from: http://www.clinicalmolecularallergy.com/content/6/1/10

(C) 2008 Mousavi et al; licensee BioMed Central Ltd.

This is an Open Access article distributed under the terms of the Creative Commons Attribution License (http://creativecommons.org/licenses/by/2.0), which permits unrestricted use, distribution, and reproduction in any medium, provided the original work is properly cited.

\begin{abstract}
Background: Mucosal-based immunotherapy has been already used as an alternative form of allergen delivery. In asthma, the poor success rate of immune modulation could be a consequence of inadequate immune modulation in the airways. Previously, we have found that subcutaneous (S.C) co-administration of a homemade allergenic extract from Chenopodium album (Ch.a) pollen and Guanine-Cytosine containing deoxynucleotides (CpG-ODNs) is effective to prevent the inflammatory responses in mouse. In this study we used $\mathrm{CPG}_{\mathrm{C}} \mathrm{Ch}$.a for immunotherapy of Ch.ainduced asthma and compared the intranasal (I.N) and S.C routes of administration concerning IFN$\gamma, \mathrm{IL}-\mathrm{IO}$ and total $\mathrm{IgE}$ responses.
\end{abstract}

Methods: Ch.a sensitized mice were treated intranasaly or subcutaneously using $C_{p G}$ and Ch.a. extract. IFN- $\gamma$, IL-10 and total IgE were measured in supernatant culture of splenocytes and bronchoalveolor lavage (BAL) fluids by ELISA. Student's $t$ test was used in the analysis of the results obtained from the test and control mice.

Results: We found that I.N administration of $\mathrm{CpG} / \mathrm{Ch} . \mathrm{a}$ in sensitized mice significantly increased the production of systemic and mucosal IFN- $\gamma$ and IL- 10 compared to phosphate buffered saline (PBS), Ch.a alone and control ODNs treated sensitized mice $(P \leq 0.00 \mathrm{I})$. On the other hand, S.C. route induced the systemic and mucosal IFN- $\gamma$ in the lower levels than in I.N one, and failed to increase systemic IL- 10 induction $(P=0.06)$. Total serum $\operatorname{lgE}$ in $\mathrm{CPG} / \mathrm{Ch}$. a treated mice in both routes showed significant decreases compared to three control groups $(P \leq 0.01)$. The amounts of IgE in BAL fluids were not measurable in all groups.

Conclusion: According to the results of this experiment we concluded that immunotherapy via the I.N co-administration of $\mathrm{CpG} / \mathrm{Ch}$.a in comparison with S.C route is more effective to stimulate the mucosal and regulatory responses in Ch.a induced asthma. 


\section{Background}

Immunomodulatory agents and their applications in allergic diseases have become one of the most investigating subjects in recent years $[1,2]$. Because of their potentials in immune response deviations, $\mathrm{CpG}-\mathrm{ODNs}$ are used to shift immune response toward $\mathrm{Th}_{1}$ and regulatory cytokine induction. These cytokines can ultimately lead to prevention or reduction of pathologic features in asthma and other allergic conditions $[3,4]$. There have been many reports on beneficial properties of CpG motifs used in combination with different antigens from all over the world [5-8]. Furthermore, the route of administration is an attractive subject among these studies $[9,10]$.

In the present study we aimed to compare a number of the immunomodulatory effects of I.N and S.C co-administration of $\mathrm{CpG}$ motifs in combination with allergen of Chenopodium album (Ch.a) in Ch.a sensitized mice. The antigen used in this study was a crude allergenic extract prepared from Ch.a pollen which is one of the most common allergenic agents in Iran. Previously we had demonstrated the potentials of this extract to develop an experimentally induced asthma in mouse. We also showed the preventive effects of $\mathrm{CpG}$ motifs administered with Ch.a extract at the sensitization stage $[11,12]$.

Since the usage of adjuvant like CpG motifs for mucosal immunotherapy was successful [13], we aimed to compare the potentials of I.N. and S.C administrations of $\mathrm{CpG} /$ allergen in mouse model of asthma. In order to compare the effects of different administration route of $\mathrm{CpG}$, we selected a number of immunological parameters such as IFN- $\gamma$, IL-10 and IgE. Indeed, the measurement of immune responses regarding $\mathrm{T}_{\mathrm{H}} 1$ and regulatory activities could be the indicators for evaluating and choosing the appropriate route for $\mathrm{CpG} /$ allergen co-administration.

\section{Methods \\ Antigen}

allergen extract was prepared according to previously reported procedure [14]. Briefly, the pollen grains collected from the flowering Ch.a. plant were immediately vacuum dried at $35^{\circ} \mathrm{C}$, purified up to $98 \%$ through sieving, defatted with acetone, dried and extracted in PBS $(0.02 \mathrm{M}, \mathrm{pH}=7.4)$ overnight at $4{ }^{\circ} \mathrm{C}$. The filtered solution then was dialyzed against PBS and sterilized by $0.22 \mu \mathrm{m}$ filtration.

\section{Oligonucleotides}

The CpG-ODNs contain two CpG motifs (ODN 1826) and control ODNs lacking CpG motifs (ODN, 1826 Control) were purchased from In vivogen, USA. The complete sequences for CPG-ODNs and ODNs control are as follows respectively: 5 '-tcc atg acg ttc ctg acg tt-3' and 5'-tcc atg agc ttc ctg agc tt-3'

\section{Animal immunization}

Inbred female BALB/c mice aged in 4-6 weeks were purchased from Razi institute in Iran. All experiments complied with the requirements of the animal care committee of Iran University of medical sciences. Using previously reported protocols $[[11,15]$ and [16]], Mice were immunized on day 1 and 7 IP with $50 \mu \mathrm{g}$ Ch.a precipitated in 4 mg aluminium hydroxide in $200 \mu \mathrm{l}$ PBS and followed by aerosol challenge of $1 \%$ Ch.a (1 mg Ch.a extract in $100 \mathrm{ml}$ PBS) on days 14 and 16 for $30 \mathrm{~min}$.

\section{Immunotherapy}

For treatment, sensitized mice were divided into I.N and S.C groups. Each group was then randomly subdivided into four (10 in each) as following:

CpG/Ch.a = sensitized mice treated with Ch.a and CpG mixture $(50 \mu \mathrm{g} / 10 \mu \mathrm{g}$ respectively $)$. Ch.a = sensitized mice treated with Ch.a alone $(50 \mu \mathrm{g})$. PBS = sensitized mice treated with PBS. ODN/Ch.a = sensitized mice treated with non CpG ODN control (50 $\mu \mathrm{g} / 10 \mu \mathrm{g}$ respectively). I.N treatment was done on day 19, 26 and 33 in I.N group as mentioned above. S.C treatment was done on day 19 and 26 for mice which were considered as S.C group. Finally, all groups of mice were secondly exposed to aerosol allergen (1\%) on day 40 and 47 for $30 \mathrm{~min}$.

\section{Sample preparation}

Blood samples were collected from all mice two days after the final antigen challenge on day 49 and separated sera were stored at $-20^{\circ} \mathrm{C}$ for IgE assays. Spleens were also excised on day 49 and single cell suspensions were cultured in complete medium $\left(5 \times 10^{6} \mathrm{cells} / \mathrm{ml}\right.$ in RPMI, $10 \%$ FCS, $100 \mathrm{U} / \mathrm{ml}$ pen/strep) in the presence of $50 \mu \mathrm{g} / \mathrm{ml}$ of allergen for $72 \mathrm{hrs}$ at $37^{\circ} \mathrm{C}$ in $5 \% \mathrm{Co} 2$. Cell culture supernatants prepared from all mice were stored at $-80^{\circ} \mathrm{C}$ for cytokine assays.

Bronchoalveolar lavage fluids were prepared according to previously reported methods $[11,12]$. Briefly, therachea was canulated and BAL fluids were obtained by lavaging lungs with two $0.5 \mathrm{ml}$ of cold PBS.

\section{Cytokine assay}

IL-10 and IFN- $\gamma$ were measured in splenocytes culture media and BAL Fluids using mouse IL-10 ELISA set, cat. no. 555252 and mouse IFN- $\gamma$ ELISA set, cat. no. 5518660 respectively (BD Biosciences, USA). Tests were done according to the manufacturer's recommendations.

IgE assay-ELISA was performed for total serum IgE assay using Becton Dickinson opteia mouse IgE set, cat no.5552448, (BD, USA). According to the manufacturer the lower detection limits of the assay system was $2 \mathrm{ng} / \mathrm{ml}$. 


\section{Statistics}

Data were expressed as mean \pm SD. Each experiment was repeated twice. Student's t-test was performed for statistic analysis.

\section{Results}

Our results demonstrated elevated levels of IFN- $\gamma$ production from splenocytes after both I.N and S.C treatment with CpG/Ch.a compared to Ch.a alone, PBS and CpG/ ODN controls $(\mathrm{P} \leq 0.001)$. Furthermore, as presented in Figure 1(a) IFN- $\gamma$ production from splenocytes in I.N treated mice both in $\mathrm{CpG} / \mathrm{Ch} . \mathrm{a}$ and in ODN/Ch.a treated mice are significantly higher than those in $\mathrm{Ch}$.a alone and PBS treated mice.

Respecting IL-10, I.N treatment with CpG/Ch.a showed significant increases in systemic IL-10 levels compared to all controls $(\mathrm{P} \leq 0.001)$. But, the mean systemic concentrations of this cytokine in S.C treated mice with CpG/ Ch.a were lower in comparison with those in Ch.a and PBS controls, and higher than those in ODN/Ch.a controls $(\mathrm{P} \leq 0.01)$ as shown in figure $1(\mathrm{~b})$.

In order to analyze the effect of I.N versus S.C administration of CpG in mucosal responses we measured the IL-10 and IFN- $\gamma$ in BAL fluids of different groups of mice. We found that IFN- $\gamma$ and IL-10 were both increased in BAL fluids and results demonstrated that independent to administration route, CpG/Ch.a treatment significantly increased the production of these cytokines $(P \leq 0.001)$. As shown in figure 1(c) and 1(d), the route of administration did not affect the production of cytokines in BAL fluids and no significant changes were shown in cytokine levels between either route of administration $(P=0.06)$.

Total serum IgE in CpG/Ch.a treated mice decreased significantly compared to control groups independent to administration routes $(P \leq 0.01)$. But the amount of IgE was not detectable in BAL fluids as shown in figure 1(e).

\section{Discussion}

At the present time there are many reports on CpG-ODNs used with different allergens $[17,18]$. But, there is no report in the literature regarding the mechanisms for immunomodulatory effects of CpG-ODNs on Ch.a induced asthma. In this study we compared the effectiveness of CpG components for I.N and S.C immunotherapy of mice sensitized by Ch.a, allergenic extract. This extract was made from one of the common allergenic pollen in our country. For this goal we evaluated a number of systemic and local immunomodulatory effects of CpG motifs in Ch.a induced asthma. We measured IFN- $\gamma$, IL-10 and IgE as the Th1, T-reg and Th2 like responses, respectively. In consistence with other reports $[6,10]$, we found in our study the increased IFN- $\gamma$ production in splenocytes cul- ture supernatants as well as in BAL fluids after CpG/Ch.a therapy. These results indicated the potentials of $\mathrm{CpG}$ motifs to enhance the systemic and local $\mathrm{Th}_{1}$ like responses in Ch.a sensitized mice. However, concerning IFN- $\gamma$ production, our results indicated that I.N administration of CPG motifs was more effective than S.C route. Thus, according to a number of studies $[19,20]$, we can suggest that this effect could be attributed to expression of TLR-9 and also the presence of dendritic cells in the nasal epithelium.

Recently, induction of IL-10 has been proposed as an important mechanism of immunotherapy [15,21]. Similarly, our data showed that I.N treatment of mice increased the systemic and mucosal levels of IL-10 as a regulatory cytokine. However, our results indicated that S.C administration of $\mathrm{CpG} / \mathrm{Ch}$. a enhanced the local elevation of this cytokine but failed to increase the systemic IL10. Interestingly, we found not only the elevation, but also the reduction in systemic IL-10 in S.C treated mice. This effect indicates the potentials of I.N but not S.C route to stimulate both the spleen and lung lymphocytes to produce IL-10 cytokine. Therefore, based on the study of Macubas et. al [13] which reported that respiratory tolerance is mediated by IL-10 producing dendtitic cells in lung leading to development of T-reg cells, we can suggest that I.N administration of CpG/Ch.a may activate the Treg populations in lung and spleen of Ch.a sensitized mice. This result could indicate the advantage of I.N route of administration in $\mathrm{CpG} / \mathrm{Ch}$. a therapy of asthmatic mice. On the other hand, we found the significant increases in IL-10 levels after I.N therapy not only with CPG, but also with non-CPG containing ODNs. These effects for CpG negative control were not observed in S.C. administration route. According to Sano et al [22] who observed that non-CpG ODNs trigger Th2-biased immune stimulation, it seems that immunoregulatory effects of DNA components could be partly due to development of T-reg responses, especially when they are used through mucosal surfaces. Considering the reports about the participation of regulatory cells and molecules in the down modulation of immune responses in asthma [21], we suggest that intranasaly co-administration of allergenic extract from Ch.a pollen and CpG motifs in Ch.a induced asthma activates the systemic and local IL-10 producing T-reg cells. However, further studies are necessary to show that the Treg cells in the lung are responsible for the induction of tolerance through the I.N administration of CpG/Ch.a. in sensitized mice.

Regarding $\mathrm{T}_{\mathrm{H}} 2$ responses, our study indicated a decrease in total serum IgE following the CpG immunotherapy. In contrast to Mo JH [17] we and Suzuki et al [23] detected the significant declines in IgE antibodies after CpG therapy. As the IgE detection in BAL fluids was impossible, we 

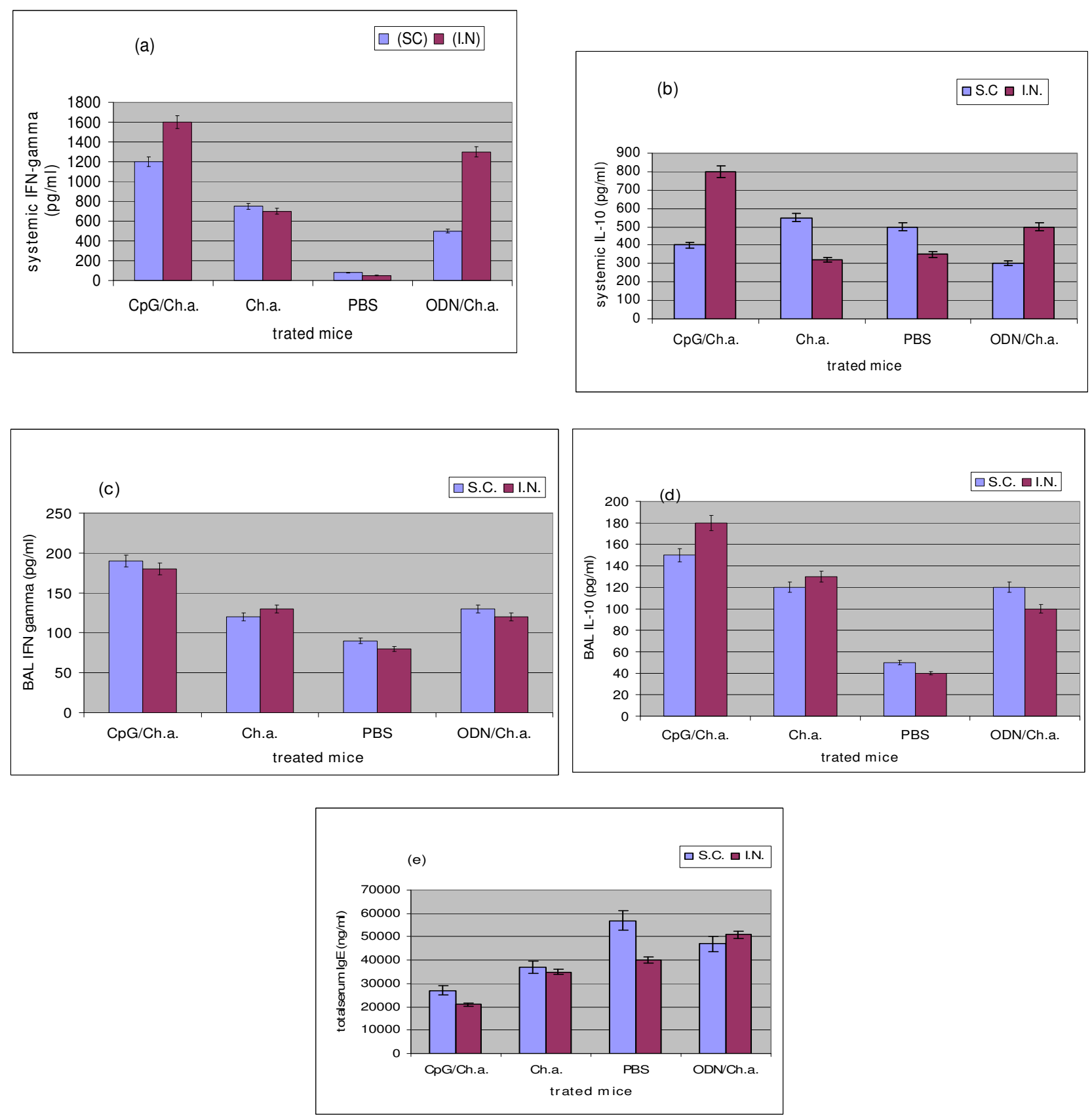

\section{Figure I}

The comparison of cytokines and antibody levels. The mean values of systemic and local concentrations of cytokines and IgE antibody measured by ELISA in S.C and I.N CpG/Ch.a treated asthmatic mice in comparison with Ch.a, PBS and ODN treated controls. (a): IFN- $\gamma$ produced by splenocytes in $\mathrm{CpG} / \mathrm{Ch}$. a treated mice are increased in both routes of administrations, (b): IL-I 0 induced by splenocytes suppressed in S.C and enhanced in I.N routes, (c and d): IFN- $\gamma$ and IL-IO in BAL fluids are equally increased in both S.C and I.N treated mice with $C_{p} G / C h . a$. (e): total serum IgE decreased in mice treated with $C_{p G /}$ Ch.a through I.N or S.C routes. $P$ values in all analysis are as $\leq 0.0$ I. 
would suggest the further evaluation of local Th2 responses such as eosinophilia in the BAL or airway hyper responsiveness.

On the other hand, In the case of route of administration and chemical component of allergen in CPG-based immunotherapy, considering other reports studding on other allergic conditions than on asthma [24], and also according to Suzuki et al [23] reporting the usefulness of CpG-ODNs in intranasal administration for control of allergic rhinitis to Japanese cedar, we showed that for immunotherapy of Ch.a sensitizes mice, nasal route which is the natural way to induce asthma could be more effective than S.C one. Moreover, in consistence with other reports indicating the advantage of allergenic proteins over peptide epitops in immunotherapy [25], our study indicated that the crude allergenic protein which is simply prepared from Ch.a pollens is a suitable material for in vivo application in mice.

\section{Conclusion}

Taken together, treatment of Ch.a induced asthma in mice via the I.N co-administration of CpG motifs with a crude extract of Ch.a pollen would be very effective compared to S.C route of administration. However, the further studies are needed to indicate the beneficial effects of this protocol in the field of human immunotherapy.

\section{Competing interests}

The authors declare that they have no competing interests.

\section{Authors' contributions}

TM and NT have designed the study and performed experiments, MM performed the statistical, MFR have worked on the draft versions of the paper. All authors have revised the final version.

\section{Acknowledgements}

This study is financially supported by Iran University of medical sciences. We wish to thank Dr Nazanin Mojtabavi for her valuable helps and critical review of the paper.

\section{References}

I. Doina M, Racilam JN, Kline M: Perspectives in asthma: Molecular use of microbial products in asthma prevention and treatment. I Allergy Clin Immunol 2005, I I 6(6): 1202-1206.

2. Jain VV, Kline JN: CpG DNA: immunomodulation and remodeling of the asthmatic airway. Expert Opin Biol Ther 2004, 4(9): $1533-40$

3. Ikeda RK, Nayar J, Cho JY, Miller M, Rodriguez M, Rosa DS: Resolution of airway inflammation following ovalbumin inhalation. Comparison of ISS DNA and corticosteroids. Am J Respir Cell Mol Biol 2003, 28: 139-I42.

4. Krieg AM: CpG motifs in bacterial DNA and their immune effects. Annu Rev Immunol 2002, 20:709-760.

5. Liu N, Ohnishi N, Ni L, Akira S, Bacon KB: CpG directly induces T-bet expression and inhibits IgGI and IgE switching in B cells. Nat Immunol 2003, 4:687-693.

6. Linghua $Z$, Xingshan T, Fengzhen Z: In vivo oral administration effects of various Oligodeoxynucleotides containing synthetic immunostimulatory motifs in the immune response to psodorabied attenuated virus vaccine in newborn piglets. Vaccine 2008, 26(2):224-233.

7. Klinman DM: Therapeutic applications of CpG-containing Oligodeoxynucleotides. Antisense Nucleic Acid Drug Dev 1998, 8(2): $18|-| 84$.

8. Hussain I, Jain VV, Kitagaki K, Businga TR, O'Shaughnessy P, Kline JN: Modulation of murine allergic rhinosinusitis by $\mathrm{CpG}$ oligodeoxynucleotides. J Laryngoscope 2002, I I 2(10):1819-26.

9. Broide DH, Stachnick G, Castaneda D, Nayar J, Miller M: Systemic administration of immunostimulatory DNA sequences mediates reversible inhibition of Th2 responses in a mouse model of asthma. J Clin Immunol 200I, 21:175-182.

10. Jain VV, Businga TR, Kitagaki K, George CL, O'Shaughnessy PT, Kline $\mathrm{JN}$ : Mucosal immunotherapy with CpG oligodeoxynucleotides reverses a murine model of chronic asthma induced by repeated antigen exposure. Am J Physiol Lung Cell Mol Physiol 2003, 285(5): LI I 37-46.

II. Mousavi T, Asadi N, Tebiyanian M: Study of Chenopodium album allergenic extract to induce allergic asthma in a murine model. Iranian Journal of Immunology 2005, 2(3):56-59.

12. Mousavi T, Salek Moghadam A, Falak R, Tebyanian M: Co-administration of CpG Oligonucleotides and Chenopodium album extract reverse IgG2a/IgG I ratios and increase IFN-gamma and IL- 10 production in a murine model of asthma. Iran J Allergy, Asthma Immunol 2008, 7(I): I-6.

13. Macaubas C, DeKruyff RH, Umetsu DT: Respiratory tolerance in the protection against asthma. Curr Drug Targets Inflamm Allergy 2003, 2(2): 175-86.

14. Mousavi T, Asadi N, Movahedi M: The comparison of conventional and WHO methods for protein determination of allergic extract. Journal of Allergy, Asthma and Immunology 2003, 2(2): $107-9$.

15. Kunihiko K, Vipul VJ, Thomas RB, Iflikhar H, Joel NK: Immunomodulatory effects of CpG oligos on established Th2 responses. Clinical and Laboratory Immunoll 2002, 9(6): 1260-1269.

16. Wild JS, Sigounas A, Sur N, Siddiqui M, Alam R, Kurimoto M, Sur S: IFN- $\gamma$ - inducing factor increases allergic sensitization, serum IgE, Th2 cytokines and airway eosinophilia in a mouse model of allergic asthma. The Journal of Immunology 2000, 164:270I-27I0.

17. Mo JH, Park SW, Rhee CS, Takabayashi K, Lee SS, Quan SH, Kim IS: Suppression of allergic response by CpG motif-house-dust mite conjugate in animal model of allergic rhinitis. Am J Rhinol 2006, 20(2):212-218.

18. Santeliz JV, Nest GV, Traquina P, Larsen E, Wills-Karp M: Amb a Ilinked CpG oligodeoxynucleotides reverse established airway hyperresponsiveness in a murine model of asthma. I Allergy Clin Immunol 2002, I 09:455-462.

19. Fransson M, Benson M, Adner M, Bjornesson S, Erjefalt J, Uddman R, cardell LO: Expression of Toll-like receptor 9 in nose, peripheral blood and bone marrow during symptomatic allergic rhinitis. Respir Rec 8: 17. 2007, feb 38

20. Hartmann E, Graefe H, Hopert A, Pries R, Rothenfusser S, Poeek H, Mack $B$ : Analysis of plasmacytoid and myeloid dendritic cells in nasal epithelium. Clin Vaccine Immunol 2006, I3(I I): 1278-86.

21. Van Scott MR, Justice JP, Bradfield JF, Enright E, Sigounas A, Sur S: IL10 reduces Th2 cytokine production and eosinophilia but augments airway reactivity in allergic mice. Am J Physiol Lung Cell Mol Physiol 2000, 278:L667-L674.

22. Sano K, Shirota H, Terui T, Hattori T, Tamura G: Oligodeoxynucleotides without CpG motifs work as adjuvant for the induction of the differentiation in a sequence-independent manner. J Immunol 2003, I 70(5):2367-2373.

23. Suzuki M, Matsumoto T, Ohta N, Min WP, Murakami S: Intranasal CpG DNA therapy during allergen exposure in allergic rhinitis. Otolaryngol Head Neck Surg 2007, 136(2):246-25I.

24. Inoue J, Yotsumoto S, Sakamoto T, Tsuchiya S, Aramaki Y: Changes in immune responses to mite antigen sentisized through barrier-disrupted skin with CPG-Oligo in mice. Biol Pharm Bull 2006, 29(2):385-387.

25. Suzuki M, Ohta N, Min WP, Matsumoto T, Min R, Zhang X, Toida K, Murakami S: Immunotherapy with CpG DNA conjugated with T-cell epitope of an allergenic Cry J 2 protein is useful for control of allergic conditions in mice. Int Immunopharmacol 2007, 7(I):46-54. 